\title{
A Geochemical Investigation of Pyrite from the Disseminated Gold Ore of Round Mountain Mine, NV
}

\author{
Blakemore, Daniel R., ${ }^{1}$ MCleod, Claire L. ${ }^{1}$ \\ KREKELER, MARK P.S. ${ }^{2}$, SHAULIS, BARRY J. ${ }^{3}$ \\ ${ }^{1}$ Department of Geology \& Environmental Earth Science, \\ Miami University, Oxford, OH 45056 \\ ${ }^{2}$ Department of Geology \& Environmental Earth Science, \\ Miami University-Hamilton, Hamilton, OH 45011 \\ ${ }^{3}$ Department of Geosciences, University of Arkansas, \\ Fayetteville, AR 72701
}

Round Mountain Nevada hosts one of the world's most prominent low sulfidation, epithermal type $\mathrm{Au}-\mathrm{Ag}$ deposits. Gold occurs at Round Mountain as both macrocrystalline gold crystals and disseminated ore, and while the vast majority of gold produced from Round Mountain is from disseminated ore, the source of disseminated ore remains poorly understood. It is well established that gold is associated with arsenic-rich pyrite at other epithermal type deposits $[1,2]$, however no published geochemical work has been completed on pyrite from Round Mountain to determine if this association holds true at this deposit.

This study utilizes scanning electron microscopy energy dispersive x-ray spectroscopy (SEM-EDS) and laser ablation inductively coupled plasma mass spectrometry (LA-ICP-MS) techniques to reveal the extent and distribution of gold concentration within pyrites from disseminated ore at Round Mountain.

Elemental analysis via SEM-EDS revealed arsenic to be a significant minor element in pyrite. It is concentrated heterogeneously and in several grains, and preferentially concentrated at the crystal margin in others. Analysis via LAICP-MS revealed gold to be present at trace, yet still potentially economically significant concentrations. Additionally, a distinct spatial correlation between arsenic and gold was observed throughout all studied pyrite grains. Trace elemental maps of $\mathrm{Se}, \mathrm{Ni}$ and $\mathrm{Ag}$ reveal apparent overgrowth textures, possibly indicating multiple generations of pyrite growth. Improving the understanding of the way gold, arsenic and other minor/trace elements are distributed revealed by SEM-EDS and LA-ICP-MS elemental mapping, could have future implications for cyanide heap leaching and ore milling efficiency at the Round Mountain gold mine.

${ }^{1}$ Cook and Chryssoulis 1990, Canadian Mineralogist, Vol. 28, pp. 1-16

${ }^{2}$ Reich et al. 2005, Geochimica et Cosmochimica Acta, Vol. 69, No. 11, pp. 2781-2796 